\title{
Debate
}

\section{Doctors as judges: the verdict on responsibility for health}

Smokers, drinkers, animal fat eaters, the inactive and the obese, they are all blamed for their potential ill health by doctors, society and their families, in western societies victim blaming is a widespread phenomenon. Doctors are encouraged or even put under pressure to judge behaviour as a tool to allocate and ration medical procedures, by governments or insurance companies that want to keep the healthcare expenditure within strict limits. In recent years the knowledge obtained by risk factor epidemiology and related to personal behaviour and lifestyle, has become more and more widely used to hold people responsible for their own health. This is not only happening within the doctor-patient relationship, ${ }^{1}$ but also in everyday social and domestic life. ${ }^{2}$ Governments and international corporations are in contrast rarely seriously blamed for the consequences their policies have for the health of the population. Although public health theory accepts the existence of biological, behavioural and societal causes of both sick persons and sick populations, ${ }^{34}$ the application of the available knowledge is clearly biased towards the individual behaviour.

However, to establish a person's responsibility we need more than just some connection between a behaviour related risk factor and a disease, even if we are dealing with an undoubted causal relation. Responsibility is a far more complex judgement, which also entails judgements regarding freedom and autonomy. In this piece we aim to clarify the conditions under which we can truly speak of a personal responsibility for health, as well as point at the limits of such a responsibility.

\section{Responsibility}

As the American philosopher Susan Wolf notes, the longer we think and talk about what responsibility really is, the more mysterious and opaque the concept becomes. ${ }^{5}$ The concept is related to the philosophical problem of free will, and that issue has been the subject of philosophy for thousands of years. Yet in everyday practice we use this concept without too much trouble. We make different judgements for irresponsible, unresponsible and responsible people. ${ }^{6}$ The irresponsible we will blame for their fault, the responsible we may praise for their result, and the unresponsible will be lifted of blame and praise. In short, presence or absence of responsibility determines our responsive treatments.

Among others the American philosopher Joel Feinberg and Susan Wolf list a number of conditions that are commonly examined to decide whether someone was indeed responsible for some deed. Firstly, we will want to know whether they are actually the ones who perform the act, meaning that they are not pushed, coerced, addicted, etc. Someone pushed under a car, or poisoned by his spouse is not responsible for respectively dangerously crossing the street, or damaging his health. Secondly, we do not want to hold anyone responsible for something they were unable to know about because the knowledge was unavailable to them. Someone who visits another country may not know all social codes and can therefore not be held responsible for violating some social rules. And thirdly some people do not know what they choose, not because the knowledge is unavailable to them, but because they lack the intellectual powers, this holds for example for babies, mentally disabled, comatose, or people in an acute state of psychosis.

As we seem to cope with such a conception of responsibility in daily life, judging examination results, or giving a fine to those who drive through a red traffic light, why would the situation for health be any different? People that are free to decide what to eat, know about good food advice, and are otherwise capable to make their own decisions, surely can be as responsible for their health as they are for the consequences of their other activities.

On the other hand we must remember that being responsible for health does not mean that health is wholly or exclusively determined by someone's actions. Totally responsible people may be involved in traffic accidents, or may fail their exams, and likewise responsible people that don't drink, don't smoke but do exercise fall ill. For there are many other factors influencing health, of which chance is certainly not the least important, which are outside an individual's influence. Still, it seems logical and wholly acceptable that people are responsible for those choices they make that influence their health. This can only hold, though, under certain conditions, namely a good enough amount of freedom, and a good enough base of knowledge.

\section{Freedom, personal choice and lifestyle}

Freedom is also a complicated notion. Sir Isaiah Berlin introduced the distinction between negative and positive freedom, negative freedom being the freedom from interference by the state or other persons. ${ }^{7}$ Positive freedom then refers to a freedom to choose certain options. Earlier we gave the example of not being pushed, this example is consistent with negative freedom, but this does not seem to be a truly sufficient type of freedom for responsibility. A poor woman in an underdeveloped country surely cannot be held responsible for not eating a healthy diet, even if she is free in the negative sense, and knows and understands what a healthy diet should be. Clearly to be able to make the right choice, the right option has to be available. The range of options available to a person is shaped and established by the physical, economic, cultural and social environment. ${ }^{8}$ It is important to realise that the ranges have a different width for different persons. Typically the wider ranges, with more options and hence also more healthy options are enjoyed by people with more power and resources. So it may come as no surprise that the pattern of occurrence of health choices in a given society is never random, nor is the pattern of disease. There are impressive socioeconomic inequalities in health in all countries. The inequalities related to socioeconomic position pervade almost every aspect of health and health care: it is found in the occurrence of accidents, ${ }^{9}$ in the occurrence of chronic diseases and the course these take,${ }^{10}$ in the occurrence of lethal diseases such as cancer, ${ }^{11}$ and in the use of health care services. Now interestingly, Dutch research showed that approximately half the socioeconomic status related differences in the Netherlands are related to structural causes that people can only with difficulty change, and the other half to more individually related lifestyle choices. ${ }^{12}$ But how individual is a choice when it is also so clearly associated with being in the lowest socioeconomic group? 
Clearly the freedom to make healthy choices is not similar for everyone in society; societal circumstances affect the positive freedom.

\section{Knowledge}

For an avid reader of newspapers and medical journals hardly a day passes without news about a recently suspected, discovered, or proven risk to our health. Within a week the Food and Drugs Administration panel on transmissible spongiform encephalopathies voted gelatine to be unsafe, ${ }^{13}$ heat was proven a risk factor for mortality in nursing homes, ${ }^{14}$ and the dangers of licking one's golf ball were described. ${ }^{15}$ Much information is contradictory, however. Recently we have seen abortion to be and not to be a major risk factor for breast cancer. ${ }^{16}{ }^{17}$ On top of that the mere quantity of risk factors can be overwhelming; there are 218 different risk factors for heart attacks, even cardiologists have problems to memorise the whole list. ${ }^{18}$ Could a lay person be expected to avoid 218 things just to take care of one organ?

On the other hand the enormous increase in this kind of knowledge in medicine has had no counterpart in an attributable parallel improvement in the prognosis of patients and incidence of diseases. ${ }^{19}{ }^{20}$ The prognosis for major causes of death like cancer or heart diseases, or for the major causes of human suffering and disability like rheumatic or psychiatric disorders, only marginally improved. And the common cold still has the same incidence, natural history, and prognosis as it had 100 years ago. Additionally the fallibility of the current medical body of knowledge to predict is enormous, not just because the traditionally poor use of scientific standards in research and practice, but also because of the widespread acceptance in medical circles of pre-logical thinking in building the medical information base. ${ }^{21} 22$

Against this background, we should realise how fallible the doctor's information base is, and how unwise it would be to use this information base for a different purpose than the strict medical practice. Even doctors are increasingly critical about the applicability of their information to clinical practice as is shown by the recent discovery by the medical mainstream of the need of an "evidence based medicine". ${ }^{23}$ We therefore cannot demand that the general public accept every bit of news about risk factors for disease uncritically.

\section{Is there room for health responsibility?}

Although we must conclude that some people can in some circumstances be held responsible for some aspects of their health, not all people should always be held responsible. Much depends on the circumstances under which they make a choice. Not only does a large part of the world population have to make their choices in circumstances of absolute or relative deprivation, the knowledge health advice is based on is often not very well founded either.

To establish whether someone is indeed responsible in a particular case is difficult, not all factors may be easy to identify. Health is also determined by someone's genetic heritage and environment. A person can hardly be held responsible for his or her genetic make up, or for his/her social environment. The establishment of someone's responsibility and guilt in criminal law is surrounded with time consuming procedures to guarantee a fair outcome, but in health care there is often no time to conduct such investigations, nor is the structure of health care suitable for such procedures. We would need health public prosecutors and health lawyers. And surely doctors should not be placed in the position of the judge.

But even if we could in individual cases establish "guilt", it may not be clear what the consequences should be. One could argue as the Dutch ethicist Inez de Beaufort does that falling ill is punishment enough for gambling with your health. ${ }^{24}$ There seems to be some poetic justice in this view. However, ascribing responsibility in health is often connected to forfeiting the claim to collectivised healthcare resources, as in insurance arrangements or a national health service. "Why should I pay for your bad behaviour?". Arguably forfeiting your right to a healthcare claim is not exactly the same as punishment, even though most people would experience it that way. A better rebuttal to the question why I should pay for your bad habits seems the answer that not only will you pay for my bad habits, but also that it won't cost you more. The health profit of most lifestyle adaptations is not very large, at the most one to a few years. ${ }^{25}{ }^{26}$ Smoking may be not only the most widely used example of a risk factor, but even be the only risk factor that really pays to give up. Smoking may not confer extra costs to you, however, as smokers die at a younger age, but not in a more expensive manner. ${ }^{27}$

In view of all this, doctors do wise to promote the circumstances under which responsibility is possible, namely guard social equity and produce and promote sound knowledge. To guard social equity doctors must develop and keep their social conscience, the production of knowledge requires good research, and the promotion of this knowledge fair understanding of what moves people when they make a health related choice. Doctors should not blame individuals for risky lifestyles. The chances this health damaging lifestyle is simply not within a person's capacity to change are great. And never should doctors let themselves be used to pass a verdict on behalf of society, which may not approve of some lifestyles. If society should wish to punish those whose lifestyle they do not approve of, this should be under no less strict rules than in criminal justice: the rules should be set in advance, and be known publicly, the principle of fair hearing should apply, and we shouldn't combine the judge, the prosecuter and the executioner in one person. Doctors do not deserve to be cast in such roles.

SUZANNE VAN DE VATHORST

Department of Philosophy, Ethics and History of Medicine, Erasmus University Rotterdam, Rotterdam, the Netherlands

CARLOS ALVAREZ-DARDET Departemento de Salud Publica, Edificio de Ciencias Sociales, Campus de San Vicente, Universidad de Alicante, Apartado de Correos 99, E-03080 Alicante, Spain

The authors wish to thank all participants for their support, and particularly Charles Erin and Inez de Beaufort for their comments on earlier versions of the paper.

Funding: this study was performed with the financial support of the BIOMED II project on Communicable Diseases, Lifestyles and Personal Responsibilities, Ethics and Rights (project number BMH4-96-1430).

1 Underwood MJ, Bailey JS. Should smokers be offered coronary bypass surgery? BMF 1993,306:1047-50.

2 Labonte R. Community health promotion strategies. In: Health promotion, an anthology. Washington: Pan American Health Organization Scientific Pubanthology. Washington: Pan Am
lication no 557, 1996:138-48.

3 Rose G. Sick individuals and sick populations. Int f Epidemiol 1985;14:32-8.

4 Susser M. Does risk factor epidemiology put epidemiology at risk? Peering into the future. F Epidemiol Community Health 1998; 52:608-11.

5 Wolf S. Freedom within reason. New York: Oxford University Press, 1990

6 Feinberg J. Harm to self. New York: Oxford University Press, 1989

7 Berlin I. Four essays on liberty. New York: Oxford University Press, 1969.

8 Milio N. Promoting health through public policies. Ontario: Canadian Public Health Association, 1986

9 Beeck EF van, Mackenbach JP, Looman CW, et al. Determinants of traffic mortality in The Netherlands: a geographical analysis. Int $\mathcal{f}$ Epidemiol 1991;20:698-706.

10 Meer JBW van der, Mackenbach JP. The course of health status among chronically ill persons: differentials by level of education. $\mathcal{F}$ Clin Epidemiol 1998;51:171-9.

11 Schrijvers CTH, Coebergh JWW, Heijden LH, et al. Socioeconomic variation in cancer survival in the Southeastern Netherlands. 1980-1989. Cancer 1995;75:2946-53.

12 Stronks K, Mheen H, van de Looman CWN, et al. Behavioural and Structural factors in the explanation of socio-economic inequalities in health: an tural factors in the explanation of socio-economic inequalities in healt
empirical analysis. Sociology of Health and Illness 1996;18:653-74.

13 Ault A. US FDA panel queries safety of gelatin. Lancet 1997,349:1305. 
14 Mackenbach JP, Borst V, Schols J. Heat-related mortality among nursing-home patients. Lancet 1997,349:1297-8.

16 Melbye M, Wohlfahrt J, Olsen JH, et al. Induced abortion and the risk of breast cancer. N Engl

17 Brind J Chinchilli VM Severs WB, et al. Induced abortion as an independent risk factor for breast cancer: a comprehensive review and meta-analysis. ent risk factor for breast cancer: a comprehensive review a F Epidemiol Community Health 1996;50:481-96.

or socio-economic differencials in mortality. Eur 7 Public Health 1994;4:131-44.

19 Mc Keown T. The role of medicine: dream, mirage or nemesis. London: Nuffield Provincial Hospital Trust, 1976.

20 Alvarez-Dardet C, Ruiz MT. Thomas McKeown and Archibald Cochrane: a journey through the diffusion of their ideas. BMF 1993;306:1252-4.

21 Alvarez-Dardet C, Gascon E, Mur P, et al. 10 year trends in the journal's publications. N Engl f Med 1985;312:1521-2.
22 Cochrane A. Effectiveness and efficiency, random reflections on health services. London: The Nuffield Provincial Hospital Trust, 1972.

23 Davidoff F, Haynes B, Sackett D, et al. Evidence based medicine. BMF 1995;310:1085-6.

24 Beaufort ID. Eigen schuld, dikke bult: een pijnlijke kwestie? Background study for "Choices in Health Care". The Hague: Distributiecentrum DOP, 1991.

25 Gunning-Schepers L. The health benefits of prevention: a simulation approach. F Health Policy 1989;12/1-2:93-129.

26 Tsevat J, Weinstein M, Williams L, et al. Expected gains in life expectancy from various coronary heart disease risk factor modifications. Circulation 1991;83:1194-201.

27 Barendregt J, Bonneux L, Maas P van der. The health care costs of smoking. N Engl f Med 1997;337:1052-7. 